\title{
Correction to: epidemiological and genomic characteristics of $A$. baumannii from different infection sites using comparative genomics
}

Xingchen Bian ${ }^{1,2,3,4}$, Xiaofen Liu 2,3,4, Xuefei Zhang ${ }^{2}$, Xin Li ${ }^{2,3,4}$, Jing Zhang ${ }^{2,3,4,5}$, Huajun Zheng ${ }^{6}$, Sichao Song ${ }^{6}$, Xiang $\mathrm{Li}^{1^{*}}$ and Meiqing Feng ${ }^{1 *}$

Correction to: BMC Genomics 22, 530 (2021). https://doi.org/10.1186/s12864-021-07842-5

Following publication of the original article [1], it was reported that there was an error in Fig. 4. The image used was a duplicate of that for Fig. 5. The correct Fig. 4 is provided in this Correction article and the original article has been updated.

The original article can be found online at https://doi.org/10.1186/s12864021-07842-5

*Correspondence: xiangli_mh@fudan.edu.cn; fmq@fudan.edu.cn

${ }^{1}$ School of Pharmacy \& Minhang Hospital, Fudan University, 826 Zhang Heng Rd, Shanghai 201203, China

Full list of author information is available at the end of the article

(c) The Author(s). 2021 Open Access This article is licensed under a Creative Commons Attribution 4.0 International License, which permits use, sharing, adaptation, distribution and reproduction in any medium or format, as long as you give appropriate credit to the original author(s) and the source, provide a link to the Creative Commons licence, and indicate if changes were made. The images or other third party material in this article are included in the article's Creative Commons licence, unless indicated otherwise in a credit line to the material. If material is not included in the article's Creative Commons licence and your intended use is not permitted by statutory regulation or exceeds the permitted use, you will need to obtain permission directly from the copyright holder. To view a copy of this licence, visit http://creativecommons.org/licenses/by/4.0/. The Creative Commons Public Domain Dedication waiver (http://creativecommons.org/publicdomain/zero/1.0/) applies to the data made available in this article, unless otherwise stated in a credit line to the data. 


\section{A}

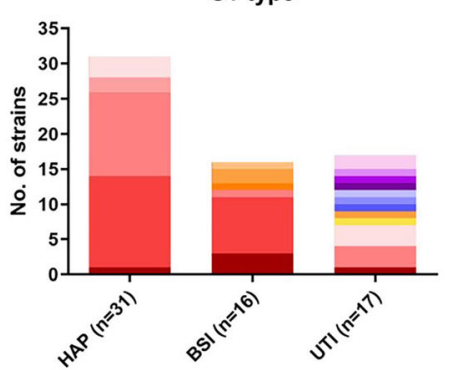

STnew ST540

- ST2245 ST429

ST2244 ST373

- ST2243 $\quad$ ST369

- ST2242 ST218

- ST852 ST208

- ST761 ST195

ST605 ST191
B

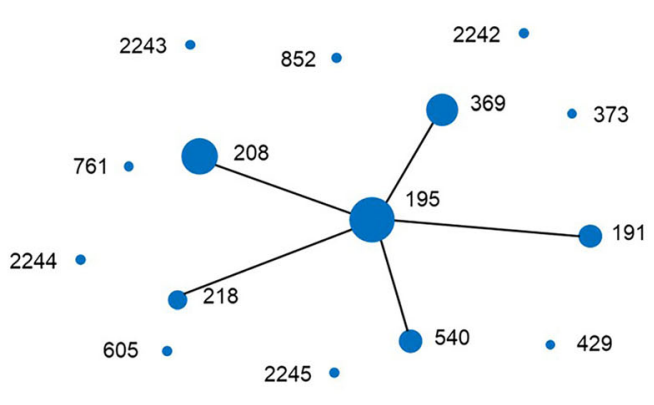

Fig. 4 Sequence types of 64 A. baumannii isolates from three infection sites (A). eBURST analysis of 64 A. baumannii isolates (B). Each solid circle represents one sequence type and its size represents the quantity of isolates of this type. Each line between solid circles indicates one allele variation

\section{Author details}

${ }^{1}$ School of Pharmacy \& Minhang Hospital, Fudan University, 826 Zhang Heng Rd, Shanghai 201203, China. ${ }^{2}$ Institute of Antibiotics, Huashan Hospital, Fudan University, Shanghai 200040, China. ${ }^{3}$ Key Laboratory of Clinical Pharmacology of Antibiotics, Shanghai 200040, China. ${ }^{4}$ Huashan Hospital, National Health Commission \& National Clinical Research Center for Aging and Medicine, Fudan University, Shanghai 200040, China. ${ }^{5}$ Phase I Unit, Huashan Hospital, Fudan University, Shanghai 200040, China. ${ }^{6}$ Chinese National Human Genome Center, Shanghai 201203, China.

\section{Published online: 08 September 2021}

\section{Reference}

1. Bian X, Liu X, Zhang X, Li X, Zhang J, Zheng H, et al. Epidemiological and genomic characteristics of Acinetobacter baumannii from different infection sites using comparative genomics. BMC Genomics. 2021;22(1):530. https:// doi.org/10.1186/s12864-021-07842-5. 